POESÍA el poema-canción Canto a la vida. En 1981 resulta ganadora del concurso Un Mundo Maravilloso, organizado por el Instituto Colombiano de Bienestar Familiar, y en el 83 recibe la primera mención del concurso Enka de literatura infantil. En 1980 publica un libro de cuentos y poemas infantiles titulado Risas y sueños.

Quizás por esta trayectoria y por su conocimiento del mundo infantil es que en ésta, su última obra poética, encontramos no sólo ese predominio del ritmo y la musicalidad popular, mencionado anteriormente, sino también un mayor logro en aquellos poemas que reproducen una danza, que hablan de un hombre que viene lleno de frutas por el camino que va a la luna, o un nocturno en el que el principal personaje es un niño ciego. Los poemas más sencillos son los más logrados. Los que más se acercan a la imaginación mítica del niño son los que nos transmiten mayor frescura.

A pesar de la aparente diversidad de temas tocados, hay unas constantes que predominan en el universo poético creado en Desviación y ensueño: El cosmos como escenario, una niña-poeta que personifica ese viaje desde sí misma y formalmente un ritmo, popular en esencia, con una musicalidad propia de la canción tradicional.

Beatriz Helena Robledo

\section{Los emisarios: respuestas que son preguntas}

\author{
Los emisarios \\ Álvaro Mutis \\ Fondo de Cultura Económica, México, \\ 1984, 120 págs.
}

Un par de versos de Al-MutamarIbn al Farsi, poeta sufí de Córdoba, sirven de epígrafe a Los emisarios. En ellos se condensa una metáfora que hace hablar al reciente libro de Álvaro Mutis de aquellas instancias que sobreviven en la complejidad de espacios y personas. Los versos en árabe proclaman: "Los emisarios que tocan a tu puerta, / tú mismo los llamaste y no lo sabes". Y el libro del poeta colombiano, a su vez se aviene a una lectura que lo obliga inexorablemente a preguntarse por qué sus poemas tocan a las puertas alargando enigmas en lugar de certezas. $\mathrm{O}$, si se prefiere, otorgando como única realidad el enigma.

Otros emisarios se internan en los poemas de Mutis para traer noticias de una voz que, como el eco, se traslada por un aire cargado de sonidos. Los emisarios del poeta son los espacios y los personajes que mejor se muestran a esa lejanía que es la memoria de un yo plural o el simulacro del tiempo en forma de acciones. Lo que no conocen las voces del libro son las instancias que oprimen o seducen, por ejemplo, al Gaviero, al observador del funeral de César Borgia, a los integrantes del cortejo que ingresará pronto a la celda de María Mihailovna. Esa carencia es la que da nuevos bríos a la voz narrativa que instala sus sospechas en cualquier ámbito que describe. Una expresión que es también detector del vacío que posee y obsequia a los ojos que descubren sospechas similares y un exacto mutismo en estos cuerpos verbales: "Era la voz del que habla porque le sería insoportable el silencio de los otros" (La visita del Gaviero).

Digámoslo de una vez: emisarios son los mensajes y éstos las brújulas para escarbar en los testimonios escondidos o devueltos a la luz. Es la travesía del Gaviero:

\section{Al terminar el valle se levanta una imponente mole de granito par- tida en medio por una hendidura sombría. Allí entra el río en un silencioso correr de las aguas que penetran con solemnidad proce- sional en la penumbra del cañón. (El cañón de Aracuriare).}

Esa mole de granito aparece en otros poemas indicando una frontera más psicológica que física. En medio de ella se espera "la inefable señal, la siempre esperada y siempre poster-

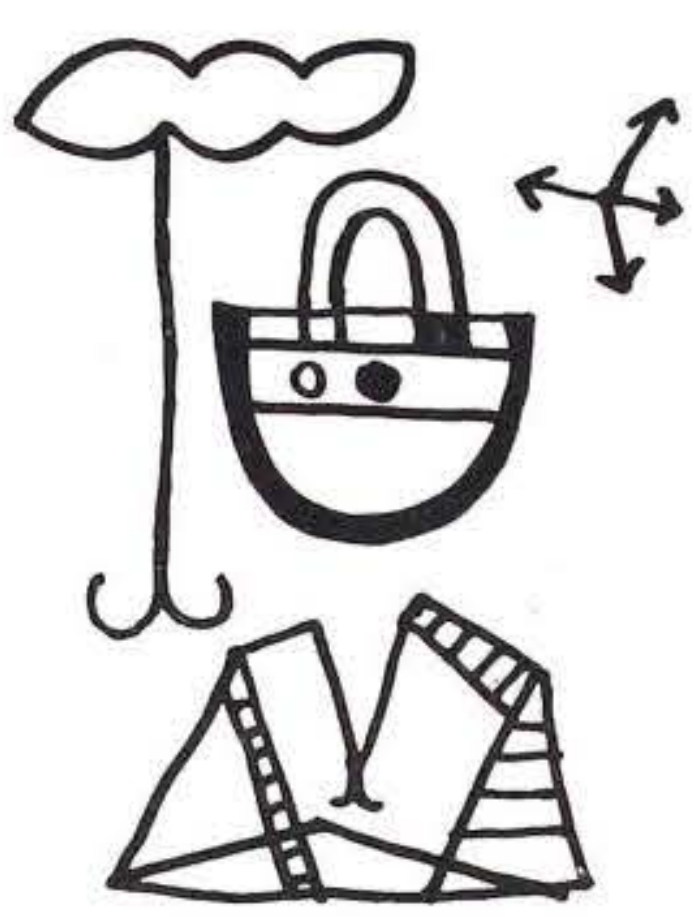

gada / señal de su definitiva disolución en la nada bienhechora" (Noticia del Hades). Esa nada es el silencio y por lo tanto la señal no puede ser expresada con palabras. Sin embargo en el viaje del Gaviero al cañón de Aracuriare, después de penetrar por esa hendidura sombría en un silencioso correr de aguas, hallamos la pista para intuir que ese paria del verbo ha llegado al centro de su lenguaje. No es sólo por el acto sexual implícito que se revela en la narración: el paso por esa abertura y más tarde la serenidad que invade al Gaviero. También del centro del lenguaje, como de la muerte, emana una quietud que lleva a la introspección. Es lo que atrae de inmediato al errabundo:

\section{El silencio conventual y tibio del paraje, su aislamiento de todo de- sorden y bullicio de los hombres y una llamada intensa, insistente, imposible de precisar en palabras y ni siquiera en pensamientos, fueron suficientes para que el $\mathrm{Ga}$ - viero sintiera el deseo de que- darse allí por un tiempo, sin otra razón o motivo que alejarse del trajín de los puertos y de la en- contrada estrella de su errancia insaciable. (El cañón de Aracu- riare).}

El Gaviero permanece dentro de la matriz que es el lenguaje haciendo un examen de conciencia hasta que surge una extraña aparición, producto de un desdoblamiento. Y luego un tercer interlocutor. Ahora bien, ese terreno en donde impera el silencio es al mismo tiempo el vientre materno, el origen de la lengua. 
¿De quién? De las voces de los emisarios, cuyas noticias de muerte se confunden con las de un habla colectiva. Esa supravoz del libro se remonta a una simultaneidad de tiempos, espacios y nombres. Una voz que por encima de las otras se deja oír prolonga la preocupación poética que encarnó el modernismo hispanoamericano: la tensión verbal ligada al sometimiento de los nombres que designan una realidad deslumbrante. El caso del Gaviero es pertinente para ilustrar de qué manera esa voz de tan larga estirpe culmina en una contemplación de todos sus fragmentos en el seno de su habla, en su silencio. Las búsquedas de esos viajes a países desconocidos encuentran una razón en ese territorio donde imaginación y experiencia son un estado mental: el poema. Y la topografía de los sueños concuerda con el preámbulo de ese vasto cuerpo sin palabras que es la muerte. De ahí que los signos y su apasionante desciframiento tengan validez para una historia personal, para la historia diacrónica y para un eco que reproduce, alterados, los íntimos susurros de la memoria. Lugares y reinos, la asunción de una identidad y el instinto de nombrar, todo concurre al éxtasis de la epifanía:

Avanzó en el empeño de encontra sus propias fronteras, sus verdaderos límites y cuando vio alejarse y perderse al protagonista de lo que tenía hasta entonces como su propia vida, quedó sólo aquel que realizaba el escrutinio simplificador. Al proseguir en su intento de conocer mejor al nuevo personaje que nacía de su más escondida esencia, una mezcla de asombro y gozo le invadió de repente: un tercer espectador le esperaba impasible y se iba delineando y cobraba forma en el centro mismo de su ser. Tuvo la certeza de que ése, que nunca había formado parte en ninguno de los episodios de su vida, era el que de cierto conocía toda la verdad, todos los senderos, todos los motivos que tejían su destino ahora presente con una desnuda evidencia que, por lo demás, en ese mismo instante supo por entero inútil y digna de ser desechada de inmediato. Pero al enfrentarse a ese absoluto testigo de sí mismo, le vino también la serena y lenificante aceptación que hacía tantos años buscaba por los estériles signos de la aventura. (El cañón de Aracuriare).

Ahora busquemos las analogías de esos signos que se adjudican al interlocutor omnisciente del Gaviero y démosles el valor al que aspiran. Deseo tácito: inmediatez de las palabras en el transcurrir de ciertas coincidencias; inscripción de un espacio poético frente a la naturaleza, desde y contra el lenguaje que la niega. Es el continuo presente que en Los emisarios está surcado por las máscaras de lo pretérito. Los modernistas expresaban el deseo de posesión de ese espacio imaginario desde una terminología que lo copaba por completo: la Europa afrancesada, el Oriente "exótico" y la mitología clásica son, por ello, las cifras precarias de su vacío. Pero hay más: el conocimiento de esa geografía no verbal (los elementos naturales podían ser capturados, de hecho, por los trucos y las trampas de la palabra) limitaba la noción del espacio poético a una apropiación de carácter subjetivo. Mucho antes del modernismo, en 1824, José María Heredia escribió su famosa alabanza de las cataratas del río Niágara. Una tímida libertad estilística denuncia la filiación romántica, pero sobre todo la confluencia de intereses del canto del poeta y las aguas del Niágara. La catarata resulta imagen de Dios como naturaleza en estado puro y es capaz de conceder la palabra al poeta que había enmudecido a causa de un dolor.

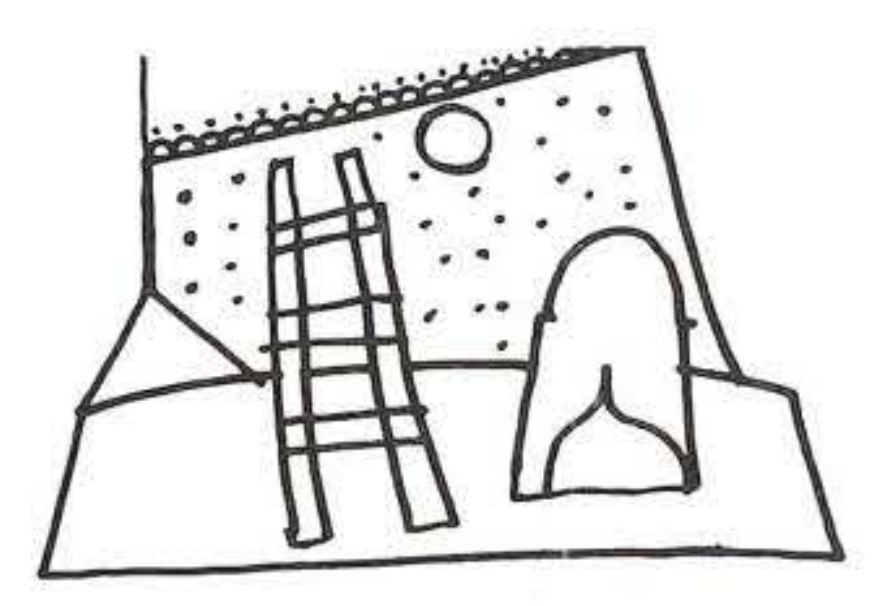

El final del poema supondrá, proféticamente, la trascendencia del Yo. El poeta capta "la esencia" del Niágara como intérprete de las obras de Dios: muda su condición y escucha desde lo alto -es ya el sol, el arco iris- los pregones terrenales de su fama, los versos que ascienden poi el agua que permanece en su caída. Es el periplo que culmina en Dios a través de la recuperación de la voz lírica. ¿Quién habla aquí? Un verbo que en un instante es el Yo que recuerda las palmeras de su patria y fabrica una ilusión: la presencia de una mujer que palpite a su lado con una intensidad semejante a la suya frente al Niágara. El Yo enfervorizado con la posesión de la palabra (el medio para acceder al Niágara "real") intenta conservarla para siempre. Es la elección romántica de una pasión exclusiva y excluyente. Arte poética: el diálogo entre el Yo y la catarata es una comunicación de carácter sacro, pues comprender el "espíritu" del Niágara es comprender los designios de su Creador. Así, mientras fuerzas diabólicas siembran guerras fratricidas y nacen "mentidos filósofos" el Niágara arrastra al Yo a un abismo que no puede recibir otro nombre que Dios: "y tu profunda voz hiere su seno / de este raudal en el eterno trueno". El poeta es penetrado por el "espíritu" de la catarata que lo conduce hasta Dios despojándolo de su cáscara de carne (y de su voz, añadiríamos). Preso en la sangre del río, vivificado, indagará por la causa final (y primera, obviamente) del proceso de búsqueda. Vuelta al origen. El estruendo del agua hizo nacer las palabras escondidas, ya inflamadas de júbilo. Las aguas del Niágara descienden a tierra para dar vida. Las palabras del poeta se elevan al cielo, fieles al Creador. La sed de infinito parece saciada: es la conciencia del entorno.

En Gutiérrez Nájera la pasión romántica comienza a teñirse de un azul-verde modernista. "Para entonces" -fechado en 1887- aparecerá, a partir de 1896, abriendo el volumen de sus poesías. El Yo del poema es una voluntad personificada que se sacrifica en ese punto en que su reino, 
la propia juventud, permanece inviolado. Pero la descripción del escenario se sustenta en una exaltación de los sentidos. Espacios abiertos: mar, cielo. Junto a ellos la apretada sensación de irrealidad -la conversión en sueño- de un ansia oculta en el final de la tarde: "Quiero morir cuando decline el día, / en alta mar y con la cara al cielo; / donde parezca un sueño la agonía, / y el alma, un ave que remonta el vuelo". Sin embargo, lo que ocurre es lo contrario: el manifiesto rigor auditivo del Yo elige en su trance más arduo los elementos afectivos (mar, cielo) y el sonido de las olas. A la hora de la muerte escuchamos el tambor del agua que ha simbolizado siempre la vida. Pero hay otra precisión en el poeta: "Morir cuando la luz triste retira / sus áureas redes de la onda verde, / y ser como ese sol que lento expira: / algo muy luminoso que se pierde". $\mathrm{Al}$ asumir la condición del sol, quien pierde es la vida y no la muerte. Esa triste luz que se retira se convierte de pronto en algo muy valioso que se aparta definitivamente. En esta transformación estética gravita el signo modernista del poema. La vida se trueca por arte, vista desde el espacio del poema: una zona inédita de la contemplación del lenguaje mismo a través de esa luminosidad dorada y verde. No es el lenguaje ordinario del mundo, opinaría Gutiérrez Nájera. En la transfiguración poeta/sol la melancolía romántica se detendrá un momento ante el naciente brillo de la joven modernista.

Esta voz cambiará de ropaje con las vanguardias de comienzos de siglo. Pero ya con Darío comenzaba a desnudarse. La fugacidad de la vida y los embelecos del amor son los tópicos que -como en el caso de Los emisarios-asoman pero no constituyen las únicas propuestas de un poema como Canción de otoño en primavera. Por algo la voz de la ausencia y el desencuentro nace de una estación desplazada en su plenitud: "Juventud, divino tesoro, / ¡ya te vas para no volver! / Cuando quiero llorar no lloro..., / y a veces lloro sin querer". El estribillo cierra cada una de las secuencias del relato de los desencantos del Yo. Todas establecen una relación victimario-víctima en su discurso amoroso, exacerbando la experiencia trágica del hablante. Dueño del conocimiento de su extrañeza, será dueño (¿o de nuevo la pertenencia?) en curiosa forma del resto de las mujeres ("pretexto de mis rimas/fantasmas de mi corazón"), ya que una historia paralela germina con renovada fatalidad. Pero de pronto el ánimo del Yo intenta neutralizar el destino infausto que su relato transmite. Si la inocencia se esfumó, al menos la sed de ella permanece. Ahora el tiempo es el que lucha con el yo pues "con el cabello gris me acerco / a los rosales del jardín". Lope de Vega debe seguir celebrando, bajo tierra, estos versos. La mención tampoco es gratuita. En el siglo de oro las penas de amor eran atribuidas retóricamente a Fortuna o a Dios. Pero lo que Darío sacraliza es el lenguaje mediante la divinización del Yo. La palabra regresa a lo numinoso por vía de lo mágico. El enigmático verso “¡Mas es mía el Alba de Oro!" guarda armoniosa contradicción con el resto del poema. No sorprende que el sentimiento de pérdida, clarísimo en el texto y reiterado de varias maneras y en distintos niveles, tenga como respuesta una afirmación concluyente. El "Alba de Oro" es la posibilidad, abierta hasta la muerte, de dar vida a los estratos de la conciencia del Yo, por más lejanos o confusos que parezcan. El poder de iluminar (Alba/Oro) celebra no sólo la inagotable energía del Yo sino atestigua el sufrimiento padecido con el correr de los años. La moraleja es un desafío que cae por su propio peso, como la vida; el Yo no desespera por el Alba de Oro, pues le pertenece hasta el fin. En otro sentido, la riqueza del Yo no es la suma de experiencias sino la capacidad de verbalizarlas. De esta seguridad hizo Darío una profesión de fe. Un poco más tarde algunos vanguardistas le habrían de poner, como se estila, un sambenito de ocasión.

Volvamos a Los emisarios y preguntemos si el tercer interlocutor del Gaviero no es una supravoz, errante también, que anhela la quietud del silencio. No sugiero que los hablantes del libro de Mutis tengan rasgos modernistas. Simplemente se me ocurre que las preocupaciones no resueltas por el modernismo, casi setenta años atrás, cobran vigencia en estos poemas. Y, lo que es más, se expresan magníficamente en un diálogo de espacios y personas que integra el pasado a un presente que se perpetúa. El excedente de fantasía del modernismo es recogido aquí por acción de los desplazamientos a España (en su versión árabe) y a un Oriente europeizado: la Rusia de los zares. Al mismo tiempo, en el trópico hallará el Gaviero la sensación de correspondencia con las voces que lo habitan. Pero también los viejos dilemas modernistas recuperan vitalidad en las diez Lieder del volumen (¿intromisión nórdica vía Eguren, De Greiff?) que aclaran las preocupaciones de todos los personajes articulándolas en breves estrofas. De la euforia guerrera al reposo del sueño funeral -y viceversa-el interés por nombrar lo que la memoria arrebata al olvido es uno de los paradigmas de Los emisarios. La sacralización del vacío también conduce a la palabra. Todos los signos que pueblan estos mensajes son preguntas por el origen de la voz común que los pronuncia. Pero, como toda expresión, ese origen es situado en lugares concretos (la otra vertiente del trópico americano) que constituyen la revelación: "Y llego a este lugar y sé que desde siempre / ha sido el centro intocado del que manan / mis sueños, la absorta savia / de mis más secretos territorios / reinos que recorro, solitario destejedor / de sus misterios" (Cádiz). Restitución de una lengua a esa España que tiene su deuda con el Islam. Perfecto ajuste de cuentas de Álvaro Mutis con ese sistema de signos al que dieron en su momento la espalda los modernistas y del que habían recibido el fuego del idioma. Una reivindicación que es el encuentro de ese lenguaje consigo mismo: "quizá porque ayer oré en el Mihrab de la Mezquita, pidiendo una señal que me entregase, así, sin motivo ni mérito alguno, / la 
certidumbre de que en esta calle [...] estaba el lugar, el único e insustituible lugar en donde todo se cumpliría para mí $[\ldots]$ y seré, hasta el último día, otro hombre o mejor, el mismo pero rescatado y dueño, desde hoy, de un lugar sobre la tierra" (Una calle de Córdoba).

En un burdel de mala muerte, en un puerto de río, el Gaviero tiene relaciones con una media hermana. Lo descubre porque en el cubículo destartalado ha visto una foto de su padre colgada en la pared. Le pregunta a la mujer por ese hombre y se entera entonces de que se trata del padre de ella. Si aprovechamos la metáfora del incesto, se trataría del padre-lenguaje que reúne al Gaviero y a su hermana en una simbólica anagnórisis. Los cuerpos filiales hablan por la sangre. Y el Gaviero sabe que se ha nutrido de innumerables e inexplicables circunstancias: "... al fin de cuentas todos estos oficios, encuentros y regiones han dejado de ser la verdadera substancia de mi vida. A tal punto que no sé cuáles nacieron de mi imaginación y cuáles pertenecen a una experiencia verdadera" (La visita del Gaviero).

Los esclarecimientos sólo se producen como adiciones de sucesos que el recuerdo considera justificables. Así, de poemas como el de Córdoba, el del gorrión en el Mexuar, el de la Alcazaba y el Lied sobre León de Greiff, es posible confeccionar una lista de alcances y elecciones de la supravoz de Los emisarios. Se reproduce un proceso de escritura grato a los modernistas: el silencio insoportable se llena de nombres. Los poemas de Mutis proponen enigmas en la medida que sus versos ayudan a solucionarlos parcialmente. ¿O será que intentan, más bien, aminorar la angustia que causarían si no dejaran indicios? Lo cierto es que ante Los emisarios se alza la pared de granito. Y extraviado en la certidumbre de ese vacío interior, el eco nos repite sus preguntas a modo de respuestas. Porque las fronteras que algún día atravesó el Gaviero para descubrir que su identidad no era unívoca, ya se encuentran clausuradas. Con Mutis, la metáfora modernista se abre

a la contemporaneidad y atiende a sus llamadas. Pero jamás agota los afanes: los macera en las aguas de ese río que el Gaviero conoce de sobra pero teme olvidar.

\section{EDGAR O'HARA}

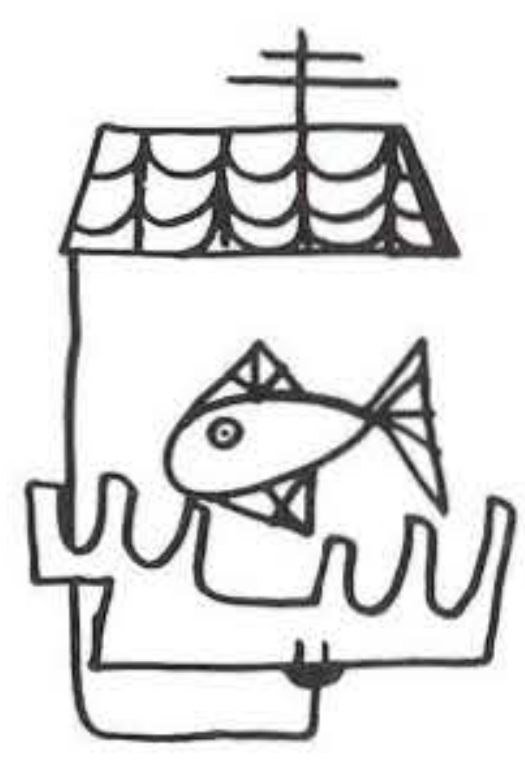

\section{Plaf y casi}

\section{Doy mi palabra \\ Miguel Iriarte \\ Fundación Simón y Lola Guberek, Bogotá, 1985, 56 págs.}

De Rolando Laserie a Andre Breton, de Jorge Artel a Rafael Maya, de Walt Whitman a Pablo Neruda, de Vinicius de Moraes a José Lezama Lima, los espígrafes de este primer libro de Miguel Iriarte (Sucre, 1957) denuncian, por decir lo menos, un gusto ecléctico, En todo caso, lo heterogéneo de sus lecturas le ha permitido escribir textos breves y rápidos que parecen cerrarse en la afanosa búsqueda final de un buen lema publicitario.

Así, por ejemplo, Zona de deseo, un poema, como su título lo indica, explícitamente erótico, termina con esta frase sorprendente: "Ahora podré salir y entrar de ti / como Pedro por su casa” (pág. 26). La frase puede hacer sonreír pero también puede llevar a preguntarnos: ¿Cuándo el coloquialismo se vuelve bajamente prosaico y cuando se carga de fuerza y asciende a poesía?

En otras frases, que oscilan entre la provocación retórica "la obscena inquietud de ser feliz” (pág. 35), o el acierto, más mesurado: "el pasatiempo / -tan de moda, siempre- / de la nostalgia" (pág. 21), vamos pal- pando mejor las configuraciones expresivas con que Iriarte arma su mundo. Un mundo, la verdad sea dicha, un tanto esquemático. El mundo de la pasión adolescente, tan brusca como cinematográfica. Esa misma pasión, luego frustrada en el llanto autoconmiserativo del bolero; y el mundo, más costumbrista, sin ninguna intención peyorativa en el término, de los vastos patios de las casas próximas al mar Caribe, con su ya inevitable olor (y sabor) de la guayaba. El mundo, entonces, de la infancia. De la madre que trata de alcanzar "estrellas frescas / para mi desayuno / con esa misma vara de tumbar limones" (pág. 52).

Un mundo que paga su óbolo a esa "vegetación nerviosa de los cuerpos" (pág. 25) confiriéndole a su poesía una vibración demasiado tensa, que prefiere descargarse en frases rotundas como golpes y no internarse, dubitativa, premonitoria, en su propia exploración interior. En su intransferible búsqueda personal. No. Aquí todos los juegos ya están dados $y$ hasta los difuntos resultan demasiado "exteriorizados", para emplear un término propio de Ernesto Cardenal, referente a poemas de este tipo. Véase este ejemplo:

\section{Se reventaron mis abarcas} en el mitín.

Estoy de pelea con mis metáforas y enredado hasta la zona de la angustia

con la madeja horrible del desvelo.

$Y$ sucio de miedo

hasta las uñas porque en el patio otra vez está mi madre

con la sagrada bata blanca de los muertos. (pág. 51)

Aquí es donde el poema debería comenzar. Aquí, lamentablemente, es donde el poema termina. El poeta, perdido entre tentaciones demasiado atrayentes -la obviedad, el desparpajo verbal, la estructura que lo obliga a concluir, con un puñetazo impactante- relega, a un segundo plano, otra dimensión, quizás más secreta pero sin lugar a dudas mucho 